\title{
Erratum to: The complexity of Platonic and Archimedean polyhedral links
}

\author{
Guang Hu • Wen-Yuan Qiu • Xiao-Sheng Cheng • \\ Shu-Ya Liu
}

Published online: 17 September 2010

(C) Springer Science+Business Media, LLC 2010

\section{Erratum to: J Math Chem (2010) 48:401-412 DOI 10.1007/s10910-010-9682-6}

The authors appreciate that Prof. Alexandru T. Balaban has indicated the wrong order of references [7-10] in our original publication.

The references [7-10] should be

7. D. Bonchev, Croat. Chem. Acta 77, 167 (2004)

8. S.M. Rajtmajer, A. Miličević, N. Trinajstić, M. Randić, D. Vukičević, J. Math. Chem. 39, 119 (2006)

9. A.T. Balaban, D. Bonchev, MATCH Commun. Math. Comput. Chem. 54, 137 (2005)

10. D. Vukičević, A.T. Balaban, J. Math. Chem. 44, 725 (2008)

The online version of the original article can be found under doi:10.1007/s10910-010-9682-6.

G. Hu · W.-Y. Qiu (凶)

Department of Chemistry, State Key Laboratory of Applied Organic Chemistry,

Lanzhou University, 730000 Lanzhou, People's Republic of China

e-mail:wyqiu@1zu.edu.cn

X.-S. Cheng · S.-Y. Liu

School of Mathematics and Statistics, Lanzhou University, 730000 Lanzhou,

People's Republic of China 